\title{
LEGISLACIÓN PETRÓLERA MEXICANA Y SU DESARROLLO FAVORABLE A LOS INTERESES ESTADOUNIDENSES E INGLESES ACERCA DEL PETRÓLEO DURANTE EL PORFIRIATO
}

\author{
Jorge Leonardo GARCÍA CAMPOS
}

\begin{abstract}
SUMARIO: I. Introducción. II. Inicios de la industria petrolera en México. III. Política y relaciones exteriores de México con Estados Unidos y Gran Bretaña durante el porfiriato. IV. Legislación sobre los hidrocarburos hasta finales del porfiriato. V. Conclusión.
\end{abstract}

\section{INTRODUCCIÓN}

Entre las descripciones que se vienen a la mente del porfiriato, de quienes estudiaron la historia patria antes de la administración de Carlos Salinas de Gortari, resalta su devoción a los intereses e inversiones extranjeras a toda costa, incluso de la soberanía y del bienestar de los mexicanos.

No fue casualidad que la expresión "México: madre de los extranjeros y madrastra de los mexicanos" adquiriera popularidad durante la larga dictadura de Díaz y la posrevolución mexicana. ${ }^{1}$ También se decía de Porfirio Díaz, y de quienes componían la administración porfirista: "Dio a su patria derrotero y viril la engrandeció; pero el gran hombre murió por su amor al extranjero. ${ }^{2}$

1 Buchenau, Jürgen, “Inversión extranjera y nacionalismo. Lo paradójico de la política internacional de Porfirio Díaz", Dimensión Antropológica, México, vol. 6, enero-abril de 1996, pp. 7-24, disponible en http://www.dimensionantropologica.inah.gob.mx/? $p=1475$.

2 Garner, Paul H., Porfirio Díaz. Entre el mito y la historia, México, Crítica, 2015, p. 201. 
En el desarrollo de la historiografía sobre Porfirio Díaz se han establecido posiciones contra la inversión extranjera en dicho periodo: "Tanto los contemporáneos de Díaz como los historiadores condenan, en particular, la supuesta búsqueda exclusiva de la inversión foránea y el trato preferencial a inversionistas y trabajadores extranjeros". "La historiografía antiporfirista ha afirmado que, con su esfuerzo por obtener el reconocimiento internacional y, sobre todo, por asegurar la inversión extranjera que su política económica necesitaba para impulsar el desarrollo, el régimen de Díaz traicionó los intereses de la nación, abriendo los brazos a los rapaces empresarios extranjeros que explotaron los recursos del país". ${ }^{4}$ Se contrasta con el ideal nacional revolucionario, más que nada cardenista, y se supone que hubo negligencia voluntaria de la administración porfirista, o peor todavía, entrega de la soberanía y de los recursos materiales del país; principalmente de un bien que aún es muy preciado: el petróleo.

"Según el antiporfirismo, el régimen de Díaz era el ejemplo máximo de la tiranía, la dictadura y la opresión, y el mismo don Porfirio era condenado por su corrupción, su autoritarismo y su traición a los intereses de la nación". ${ }^{5}$ Los historiadores "coinciden en que la apertura comercial enriqueció sólo a un número relativamente reducido de individuos, incrementó la dependencia del país respecto de Estados Unidos, despilfarró los recursos nacionales y aceleró el proceso de desamortización de las tierras indígenas". 6

El antiporfirista Luis Lara Pardo decía de este periodo histórico: "Bajo los oropeles de la abundancia y la prosperidad, comenzaron a aparecer la crueldad, la intransigencia, la ambición sin límites y el egoísmo del César. Entonces pudo verse que las verdaderas características de su régimen eran dos: exterminio y prostitución". ${ }^{7}$

Daniel Cosío Villegas —quien coordinó entre 1955 y 1972 la Historia moderna de México - señaló que Porfirio Díaz "no era ni un ángel ni un demonio, ni tampoco mezcla de los dos" ${ }^{8}$ Por lo anterior, pueden considerarse los dos lados de la historia: el porfiriato, en el cual se vendió casi gratis el petróleo de México, como proceso histórico opuesto a la expropiación petrolera de Lázaro Cárdenas en 1938; o bien, como una etapa histó-

\footnotetext{
3 Buchenau, op. cit.

4 Garner, op. cit., p. 201.

5 Ibidem, p. 26.

6 Buchenau, op. cit.

7 Garner, op. cit., p. 30.

8 Ibidem, p. 32.
} 
rica durante la cual se consideraba al petróleo como algo no esencial, dada su escasez, por lo que se debía incentivar la inversión extranjera mediante amplias facilidades.

El presente artículo se decanta por la segunda opción, aunque no difiere en gran medida del primero. Entonces, para evaluar la legislación petrolera desarrollada durante el porfiriato, hay que considerar varios aspectos: el petróleo no se consideraba tan abundante y tan útil como lo llegó a ser después; el desarrollo de las inversiones extranjeras necesarias para el desarrollo económico del país necesitaban de ciertas leyes laxas que se podrían endurecer más tarde; pero también habría que mirar la política exterior porfirista, como gran parte del porfiriato, a través de la perspectiva del siglo XIX y no del nacionalismo revolucionario.

También la legislación petrolera, desarrollada durante el porfiriato, habría que evaluarla dentro de los objetivos políticos y económicos de todos los gobiernos liberales mexicanos posteriores a $1855 .{ }^{9}$ Los principales objetivos de estos gobiernos eran conseguir la soberanía nacional en general y el reconocimiento extranjero de la administración en turno, en particular, e insertarse en la "economía-mundo" o proceso de la globalización del siglo XIX. La cuestión era conciliar la defensa de la soberanía con la apertura al capital extranjero, porque el capital nacional era muy poco. Conciliar desarrollo material y soberanía sigue siendo un gran riesgo, ante todo en cuestiones de bienes materiales al que se le da cierto valor extraeconómico.

"Orden y progreso" era la máxima del porfiriato, adoptado de la filosofía positivista. Orden era la búsqueda de la paz política, aunque se tratara de una pax militarizada mediante el ejército o La Acordada, o se escondiesen los problemas "debajo de la alfombra". Progreso material era el otro objetivo; para ello era necesario un entramado legislativo e institucional que propiciase la inversión extranjera necesaria para el desarrollo nacional, porque - como ya se mencionó- el capital de origen mexicano era muy escaso. ${ }^{10}$

\section{INICIOS DE LA INDUSTRIA PETROLERA EN MÉXICO}

La historia moderna de la industria petrolera comenzó en 1859 en la población de Titusville, Pennsylvania. Al principio el petróleo servía como iluminante y medicamento. Se desarrolló dicha industria gracias al invento del motor de combustión interna para los automóviles; cronológicamente casi a

\footnotetext{
9 Ibidem, p. 202.

10 Ibidem, p. 203.
} 
la par del proceso histórico de la Revolución mexicana que empezó en 1910, no realmente durante el porfiriato.

Hasta 1910, el petróleo mexicano no le era esencial a México, Estados Unidos, Gran Bretaña, ni a ningún otro país; pero durante el porfiriato, el petróleo mexicano sí fue dominado por el capital externo; de hecho, lo fue hasta 1938. Durante este periodo, Estados Unidos produjo las dos terceras partes del combustible extraído en el mundo, además de que la demanda interna estadounidense era cubierta por su propia producción. Sólo el petróleo mexicano le interesaba a Estados Unidos para satisfacer en parte la demanda mundial. ${ }^{11}$

En 1868, el médico estadounidense Adolfo A. Autrey organiza la Compañía Explotadora de Petróleo del Golfo de México, primera empresa que extrajo petróleo de pozos perforados y produjo destilados en escala pequeña. Sus operaciones se localizaron en la región veracruzana de El Cuguas, próxima a Papantla. La Waters-Pierce Oil Company se establece en México en 1887, para refinar petróleo de origen estadounidense en las ciudades de México, Tampico, Veracruz y Monterrey.

Entre 1901 y 1910 se habla de la primera etapa de la industria petrolera mexicana, su producción era modesta y poco importante su ritmo de crecimiento. A los ojos de la administración porfirista, la actividad de la explotación petrolera no era central, como sí lo era la minera, en plata o cobre.

El petrolero estadounidense Edward L. Doheny viaja a México en mayo de 1900, para explorar las emanaciones de petróleo en la región de la huasteca potosina; luego de adquirir los derechos de varios terrenos en la zona, organiza en noviembre en la ciudad de Los Ángeles, California, la Mexican Petroleum Company of California e inicia la explotación petrolera en la zona.

Porfirio Díaz veía con optimismo su uso para ferrocarriles, y en la industria minera y eléctrica. ${ }^{12}$ Para estimularla hubo varias exenciones fiscales: libre importación de maquinaria y los impuestos internos, a excepción del timbre, por 10 años. ${ }^{13}$

En 1901 ya se explotaba el primer pozo de valor comercial El Ébano; en 1908 ya estaba en auge dicha industria en México; y en 1910 se explotaban lo que se consideraban grandes yacimientos como El Ébano por Doheny y

11 Meyer, Lorenzo, México y los Estados Unidos en el conflicto petrolero 1917-1942, México, El Colegio de México, 1981, p. 14.

12 Idem.

13 Ibidem, pp. 12-15. 
Campoacán y San Cristóbal por el inglés Weetman Pearson, y en 1911 ya se exportaba petróleo.

Edward L. Doheny era el típico empresario estadounidense en América Latina: poco o casi nada escrupuloso, buscaba de aliados a la élite política y buscaba riqueza abundante y fácil; en fin, un rudo aventurero. En 1887 invirtió por primera vez en México en la industria minera, y en 1892 compró terrenos en Tampico porque supuso que habría petróleo. Su empresa, Mexican Petroleum Company of California, nunca estuvo registrada en México, sólo en Estados Unidos; esto para que estuviera siempre protegida por la embajada de Estados Unidos en el país. Porfirio Díaz le hizo prometer que si decidía vender sus intereses en México se los ofreciera primero al Gobierno mexicano, en lugar de a la Standard Oil, para que no se involucrara más dicho monopolio en México.

El gran rival de Doheny y otros empresarios estadounidenses, como Henry Clay Pierce, fue Weetman Pearson, a quien se le conoce como "el contratista de don Porfirio". ${ }^{14}$ Este empresario de origen inglés primero invirtió en ferrocarriles y obras de saneamiento público en México; mientras construía el Ferrocarril de Tehuantepec, se propuso explotar también el petróleo mexicano por las oportunidades que ofrecía. Este empresario se relacionaba bien con la élite porfirista, porque proporcionaba cierto equilibrio frente a los intereses estadounidenses.

Tanto a Doheny como a Pearson, el mismo Porfirio Díaz les ofreció privilegios fiscales, como la libre importación de maquinaria y la exención de impuestos internos, menos el timbre, por 10 años.

\section{Política y Relaciones eXteriores de MÉXico con Estados UNIDOS Y GRAN BRETAÑA DURANTE EL PORFIRIATO}

Durante el porfiriato, 1876-1910, la política exterior mexicana se insertó en un contexto internacional dominado, en primera instancia, por las potencias europeas: "Inglaterra, Francia, Alemania [...] y en las postrimerías del siglo XIX por [...] Estados Unidos". Éstas eran industrializadas, buscaban colocar su excedente de mercancías, obtener materias primas baratas en naciones periféricas, como México, y el objetivo de algunos de tales empresarios era poseer parte de las riquezas de dichos países.

14 Connolly, Priscilla, El contratista de don Porfirio. Obras públicas, deuda y desarrollo desigual, México, Fondo de Cultura Económica-El Colegio de Michoacán-Universidad Autónoma Metropolitana, 1996. 
Sin duda alguna, la potencia mundial en la segunda mitad del siglo XIX fue Gran Bretaña (en lo industrial, comercial y en el campo de las finanzas mundiales). Estados Unidos era potencia media. La potencia media en decadencia era Francia (aunque siguió siendo potencia, por su lenguaje, cultura y avances científicos). De eso eran plenamente conscientes Porfirio Díaz e Ignacio Mariscal, el secretario de Relaciones Exteriores desde 1880 bajo la presidencia de Manuel González hasta 1910 (año en que murió). Inglaterra empezaría a ser reemplazada, como país hegemónico, por Estados Unidos hacia finales del siglo XIX. Estados Unidos, en 1898, no era tan sólo un país industrializado, sino que empezaría a tener poder político, militar y económico hacia el Caribe y el Pacífico, al arrebatarle a España sus últimas colonias: Cuba, Puerto Rico, Filipinas y Guam.

Porfirio Díaz deseaba mostrar al mundo un México de "paz y progreso", en otras palabras, que México era digno receptor de inversiones extranjeras porque ya se tenía la mencionada paz interna.

El objetivo central de la política exterior mexicana era la inversión extranjera en nuestro país, sin perder soberanía o que ésta no fuera gravemente afectada. Los países que más podían ofrecer inversión a México bajo el porfiriato eran Gran Bretaña y Estados Unidos, pero esa inversión tenía un alto costo debido al intervencionismo y proteccionismo hacia sus ciudadanos e inversiones de ambos países, especialmente de Estados Unidos.

La política exterior mexicana durante el porfiriato — según se constata en la totalidad de la obra de Daniel Cosío Villegas sobre Estados Unidos y Porfirio Díaz - era de equilibrio entre el creciente poder de Estados Unidos (debido a su expansionismo) y las potencias europeas, en específico Gran Bretaña.

En el inicio de la administración porfirista, el ministro plenipotenciario de México ante Estados Unidos era Matías Romero (quien ocupaba el cargo desde la presidencia de Benito Juárez, salvo el periodo de octubre de 1867 hasta mayo de 1868, en que fue secretario de Hacienda y sería el primer mexicano que tendría el título de embajador ante dicho país en 1898); éste buscaba una "relación especial" con el país que ya se perfilaba como un coloso con ambiciones mundiales.

Porfirio Díaz era un gran admirador del pueblo estadounidense por su desarrollo material e intelectual, y quería imitar su modelo político y de explotación de recursos naturales, ${ }^{15}$ pero temía que sus ambiciones chocaran

15 Garner, Paul H., Porfirio Díaz. Del héroe al dictador: una biografía politica, México, Planeta, 2004, pp. 146 y 147. 
con la soberanía mexicana y latinoamericana en general, como se demostró en la invasión a Cuba en 1898, la participación estadounidense en Panamá en 1903, en la separación de ésta de Colombia para construir el Canal Interoceánico, el asalto a Nicaragua en 1909, etcétera. En todas estas ocasiones el gobierno de Díaz se dijo oficialmente neutral; pero, por ejemplo, Díaz apoyó con su propio dinero la independencia de Cuba y con apoyo moral a José Martí; se veía con intranquilidad la creación de Panamá como país y se dio asilo a José Santos Zelaya (presidente derrocado por la guerrilla nicaragüense apoyada por Estados Unidos). ${ }^{16}$

Por lo tanto, podemos deducir que Porfirio Díaz deseaba que vinieran inversiones estadounidenses, pero que el precio por ello no fuera tan alto. ${ }^{17}$ Se puede decir que la política exterior entre México y Estados Unidos, en el periodo 1876-1910, fue inconsistente y contradictoria a lo largo de dicho tiempo, pues hubo momentos de confrontación, pero también de cordialidad. Las dos naciones deseaban una política que fuera conveniente para ambos países, ya que les favorecía tener una frontera tranquila, así como la paz y prosperidad en ambos lados de la frontera.

Al finalizar el siglo XIX, Estados Unidos necesitaba exportar capitales para equilibrar su balanza de pagos, a pesar de que no era un exportador neto de mercancías (al contrario, era importador neto aún). En ese fin de siglo (XIX) y el comienzo de otro (siglo XX), los círculos políticos y financieros se vislumbraban como el centro financiero del orbe; por lo que deseaban invertir en países periféricos, como México, para explotar sus materias primas.

Desde el comienzo del siglo XX, con la presidencia de Theodore Roosevelt (1901-1909), se empieza a practicar lo que se ha llamado la "diplomacia del dólar". Ésta se puede definir como defensa de los intereses económicos de los capitalistas estadounidenses en el exterior. ${ }^{18}$ Esta política se aplicaba hacia América Latina, en general, y en México, en particular. Estados Unidos buscaba defender los intereses de su próspera burguesía, y asegurar sus intereses en el exterior: "Con el desarrollo de nuestras industrias, el comercio exterior de Estados Unidos deberá convertirse rápidamente en un factor cada vez más esencial para la prosperidad económica [...] el

\footnotetext{
16 Katz, Friedrich, La guerra secreta en México, México, Era, 1984, vol. 1, p. 51.

17 Garner, Porfirio Díaz. Del héroe..., cit., pp. 144-156.

18 Mayer, Alicia, "La política del Gobierno de los Estados Unidos hacia México, noviembre de 1911 a febrero de 1913”, Estudios de Historia Moderna y Contemporánea de México, México, UNAM, Instituto de Investigaciones Históricas, 1990, vol. 13, doc. 173, p. 202.
} 
Gobierno de Estados Unidos proporcionará todo el apoyo necesario a las empresas americanas en el extranjero siempre que las considere legítimas y provechosas". ${ }^{19}$

Howard Taft se daría a conocer como el campeón de la "diplomacia del dólar". Esta política ("diplomacia del dólar") se basaba en que los businessmen estadounidenses le hacían un favor a la humanidad y a los estadounidenses en nombre de la doctrina del utilitarismo (hacerle un bien mayor al mayor número de personas); bajo esta política era obligación del Gobierno de Estados Unidos defender los intereses de sus businessmen en países periféricos como México, el resto de Hispanoamérica y el mundo en general. Se tenía que defender el concepto de propiedad anglosajón como derecho universal a la propiedad privada absoluta e inalienable; la defensa de dicho derecho (derecho de propiedad, entendido de la manera en que lo concebían el filósofo inglés John Locke y el founding father estadounidense Thomas Jefferson) se tenía que hacer fundamentalmente en países caóticos, como los hispanoamericanos, en general, y México, en particular.

Porfirio Díaz buscaba que México fuera una nación estable política y socialmente, y que dicha estabilidad se convirtiera en progreso; después de estabilizar el país, establecer un "orden" en la política y sociedad, se debía atraer las inversiones extranjeras a falta de grandes capitalistas nacionales para buscar el "progreso", y de esa manera cumplir, aunque sólo para las élites y con pocos efectos positivos para la clase trabajadora, el lema positivista de "orden y progreso". Por ello el mismo Porfirio Díaz conversaba con grandes personalidades estadounidenses, como el petrolero Edward L. Doheny, y "tejía" una relación de confianza mutua en el que se aseguraba una inversión para el país y utilidades para el inversor bajo la seguridad y estabilidad del país. ${ }^{20}$ Las conversaciones de Porfirio Díaz con inversionistas estadounidenses, como Edward L. Doheny, giraban, en la búsqueda de un pacto "ganar-ganar" para México, el régimen y el inversor; progreso para México a cambio de orden, estabilidad económica y social, a cambio

19 Taft, William Howard, "Discurso ante el United States Congress", 3 de diciembre de 1912, cit. en Núñez, Silvia y Zermeño, Guillermo (comps.), EUA. Documentos de su historia política, México, Instituto de Investigaciones Doctor José María Luis Mora, 1988, vol. III, p. 608. Aunque es posterior ese discurso a la delimitación temporal propuesta en este artículo, da una idea de la política seguida desde Theodore Roosevelt (1901-1909), quien estableció la "diplomacia del dólar" como parte de la política exterior estadounidenses, seguida por su sucesor Howard Taft.

20 Vázquez, Josefina Zoraida y Meyer, Lorenzo, México frente a Estados Unidos. Un ensayo histórico, 1776-2000, México, Fondo de Cultura Económica, 2006, p. 91. 
de utilidades seguras y crecientes para el inversor. ${ }^{21}$ Henry Lane Wilson, embajador de Estados Unidos en México, sabía de las conversaciones entre Porfirio Díaz e inversionistas estadounidenses, y sostuvo que eran conversaciones cordiales, en las cuales no había sobornos, fraudes o algo similar, y todas las concesiones hechas a los inversionistas, sin importar su nacionalidad, eran conseguidas honestamente, bajo leyes o contratos entre empresa y Gobierno federal. ${ }^{22}$

De Gran Bretaña se buscaban inversiones, pero también que balanceara el creciente poder económico y político de Estados Unidos; aunque se pagaba un precio por esto, porque sus ciudadanos alertaban a la embajada británica, al igual que lo hacían los estadounidenses, cuando veían mínimamente sus intereses dañados; por ejemplo, se generaba un equilibrio entre el poder de Estados Unidos con el capital inglés al contratar a Weetman Pearson para construir el Ferrocarril Nacional de Tehuantepec (con el cual se pensaba en un principio hacer el Canal Interoceánico, en lugar de Panamá o Nicaragua), y no a una empresa estadounidense, situación que creó tensión con Estados Unidos. ${ }^{23}$

Las relaciones diplomáticas (del Gobierno británico con el mexicano) e internacionales (agentes privados ingleses con el Gobierno mexicano, el régimen porfirista y el mismo Porfirio Díaz) tuvieron un auge en el porfiriato. Lorenzo Meyer, a esta etapa de las relaciones anglomexicanas (1876-1911), le llama "época dorada", ${ }^{24}$ porque no hubo otra igual desde la Independencia; con la caída del régimen de Porfirio Díaz aquéllas entrarían en un vertiginoso declive, y actualmente los vínculos con tal Gobierno son muy débiles.

Del Gobierno británico se esperaba que atemperara el poder que el Gobierno de Estados Unidos podría ejercer sobre el régimen porfirista. De los empresarios británicos, que invirtieran en el país para que hubiera "progreso", y que balancearan el poder de los trusts de origen estadounidense como

21 Testimonio de Henry Lane Wilson frente al United States Congress, Senate Commitee of Foreign Relations, Investigations of Mexican Affairs. Preliminary Report and Hearings of the Committee on Foreign Relations United States pursuant to Senate Resolution num. 106 Directing the Committee on Foreign Relations to Investigate the Matter of Outrages on Citizens of the United States in Mexico, 66o. Congreso, 2a. sesión, Washington, D. C., 1920, p. 2250.

22 Ibidem, pp. 2251 y 2252.

23 Garner, Porfirio Díaz. Del héroe..., cit., p. 154.

24 Meyer, Lorenzo, Su majestad británica contra la Revolución mexicana, 1900-1950. El fin de un imperio informal, México, El Colegio de México, 1991. 
Waters-Pierce Oil Company; a Weetman Pearson (quien fuera accionista principal de la petrolera El Águila, del Ferrocarril Nacional de Tehuantepec, de Mexican Light \& Power Co., etcétera) se le dieron, en 1908, exenciones fiscales, tierras, tarifas preferenciales en Ferrocarriles Nacionales de México y privilegios, con tal de que balanceara el poder económico que ejercía Henry Clay Pierce (socio minoritario de Waters-Pierce Oil Company y del Ferrocarril Central: compañía ferrocarrilera que le sería expropiada para formar, en consolidación con otras líneas ferrocarrileras, Ferrocarriles Nacionales de México).

En los inicios del siglo XX, el grueso del capital colocado en México y proveniente de Gran Bretaña se encontraba invertido en los ferrocarriles. La casa Speyer \& Cía controlaba el Ferrocarril Mexicano desde 1873; pero entraría la competencia estadounidense con el Ferrocarril Central de Henry Clay Pierce. Luego Weetman Pearson invertiría en Ferrocarril Nacional de Tehuantepec, y dicha lucha se trasladaría al campo petrolero.

Porfirio Díaz deseaba mostrar seriedad en sus relaciones exteriores e internacionales, ya que esto sería la base de la relación britano-mexicana durante el porfiriato, algo que Lorenzo Meyer llama "una relación entre caballeros" (gentleman en inglés, rememorando esa figura proveniente del medioevo que cumple siempre lo que dice; porque Porfirio Díaz se portaría frente a Gran Bretaña y a los empresarios ingleses como tal).

El valor de las inversiones de los súbditos británicos en México, en 1906, era alto, y México veía en Gran Bretaña una potencia con la cual balancear la relación con Estados Unidos, principalmente, con las inversiones inglesas en los ramos del petróleo, electricidad, minería y ferrocarriles. Pero desde 1895 el comercio y las inversiones británicas eran menores que las estadounidenses, y por ello se buscaba con mayor intensidad balancear el poder económico estadounidense (en 1876, al iniciarse el porfiriato, el 35\% del comercio exterior mexicano se realizaba con Gran Bretaña; en 1895, era del $20 \%$, y en 1920 tan sólo el 12\%. En contraste, en 1876, el 35\% se realizaba con Estados Unidos; en 1895, el 50\%, y en 1920, el 80\%. ${ }^{25}$

Porfirio Díaz deseaba que los trusts estadounidenses no dominaran en sus respectivos ramos el mercado mexicano. Por ejemplo, el formado por Henry Clay Pierce, quien era considerado por el régimen porfirista como

25 Kuntz Ficker, Sandra, "Las oleadas de americanización en el comercio exterior de México, 1880-1948”, Secuencia, núm. 57, octubre-diciembre de 2003, p. 166 (interpretación de gráfica). 
alguien perjudicial a los intereses mexicanos por "jugar rudo" y querer dominar el mercado mexicano.

Por ello quiso atraer al empresario inglés Weetman Pearson, un empresario capitalista moderno global, con una estructura de propiedad característica de etapas anteriores del capitalismo (mercantilismo). En 1889, Porfirio Díaz quería construir un "gran canal" o drenaje para el Valle de México, y para ello primero le encargó dicha obra a una empresa estadounidense cuyo intento resultó fallido; por ello le encomendó la mencionada labor a la compañía de Pearson (Pearson \& Sons). El trato directo, mediante intérprete, entre Pearson y Porfirio Díaz empezó desde ese año. Pearson, según lo describe Connolly, ${ }^{26}$ fue un empresario de origen inglés que hizo varias obras durante el porfiriato, principalmente la construcción de ferrocarriles y líneas de navegación (en Veracruz, con la ruta de Juile a San Nicolás y de Minatitlán a Tehuantepec en 1896; de Veracruz a Minatitlán en el mismo año; el Ferrocarril Nacional de Tehuantepec en 1899 y la Compañía de Navegación de los Ríos de Sotavento en Veracruz); en electricidad y tranvías (Veracruz Electric Light Power, Puebla Tramway Light, la Compañía Eléctrica de Orizaba, la Compañía Eléctrica de Córdoba, la Tampico Electric Light); en minería (El Oro Mining Co. y la Cometa de Oro Mining Co.); en agricultura y ganadería (Veracruz Land and Cattle Co.). Con sus inversiones en esos ramos se fue ganando el aprecio y amistad del presidente Porfirio Díaz (Porfirio Díaz hijo, "Porfirito", fue accionista en El Águila); e incluso, a la caída del régimen porfirista, invitó a la familia Díaz a la mansión Paddockhurst, en Sussex. Mientras construía el ferrocarril en Tehuantepec, obtuvo del presidente Porfirio Díaz concesiones petroleras que le permitirían fundar en 1901 El Águila. Hallaría el pozo "Dos Bocas", uno de los pozos más ricos de México. De Pearson se ha dicho que, después de Hernán Cortés, es quizá el que ha extraído más riquezas de México. Se le conocería como lord "member from Mexico", por sus ausencias del parlamento inglés y porque cuando se tocaba un tema concerniente a México, él seguramente diría qué hacer; y el conocido Hospital Inglés en la Ciudad de México "el ABC" (American British Cowdray Hospital) lleva su título nobiliario (lord vizconde de Cowdray). La compañía petrolera más importante durante el porfiriato y hasta la nacionalización petrolera acaecida el 18 de marzo de 1938 sería la compañía El Águila de Weetman Pearson.

Pearson, después de concluir el "gran canal" de la Ciudad de México dos años antes de lo estipulado, había logrado establecer vínculos políticos con

26 Connolly, Priscilla, op. cit. 
la administración porfirista y además con el mismo Porfirio Díaz. Entre sus socios políticos estaban Manuel Romero Rubio (secretario de Gobernación desde 1884, hasta su muerte acaecida en 1895) y José Yves Limantour (secretario de Hacienda desde 1893 hasta el fin del régimen); luego sumaría a personajes como el gobernador de la Ciudad de México, Guillermo de Landa y Escandón, y al mismo Porfirio Díaz hijo.

La encomienda de Porfirio Díaz a Pearson y al estadounidense Edward L. Doheny (de la Huasteca Petroleum Company), quienes conocían personalmente al presidente y pactaron con él las condiciones de ejercer sus negocios en México, era lograr que abastecieran de combustible no importado a los ferrocarriles (lo contrario que hacía Henry Clay Pierce, quien importaba crudo estadounidense y lo refinaba en México con el fin de reexportarlo), para propiciar que el país fuera un mercado modesto de petróleo, pero con el propósito fundamental de crearle competencia a la Waters-Pierce Company.

Como ya se mencionó, en el porfiriato se extendería la lucha entre ingleses y estadounidenses en México al mercado de la minería y de los ferrocarriles, así como al mercado petrolero, en especial entre el estadounidense Henry Clay Pierce y Weetman Pearson.

\section{LEGISLACIÓN SOBRE LOS HIDROCARBUROS HASTA FINALES DEL PORFIRIATO}

Friedrich Katz indica que había resentimiento del pueblo mexicano debido a las grandes concesiones realizadas a los estadounidenses; entre éstas, el haber otorgado concesiones para explotar los campos petroleros a compañías extranjeras, entre las cuales predominaban las estadounidenses. Al haberlas exentado también de los impuestos de exportación del producto crudo o refinado, privó al pueblo mexicano de único medio a su disposición para derivar algún beneficio de la explotación de su gran riqueza nacional.

Según el capítulo dedicado al tema petrolero, en Historia moderna de México, ${ }^{27}$ se consideraba que en México no había mucho petróleo y que el país, al no ser industrializado, no lo necesitaba; es decir, no necesitábamos mucho del petróleo, pero el mercado mundial sí. Esta afirmación viene del hecho de que dos geólogos tenían dos certezas contrastantes entre sí: Juan Villarela (considerado experto en el tema) consideraba que geológicamente México no tenía las condiciones para albergar pozos petroleros; en cam-

27 Cosío Villegas, Daniel (coord.), Historia moderna de México, México, Hermes, 1983. 
bio, un novato como Ezequiel Ordóñez en 1904 decía que en México había petróleo en cantidades exorbitantes. El último fue consejero de Edward L. Doheny, quien siguió los señalamientos del novato geólogo. En un ambiente de desconocimiento sobre el potencial petrolero de México, se inició el cambio de legislación sobre hidrocarburos: se pretendía seguir los modernos códigos mineros de Francia, Gran Bretaña y Estados Unidos. ${ }^{28}$ Además, esto era resultado del liberalismo económico del porfiriato (permitir la mayor inversión extranjera, por la falta de grandes capitales nacionales, a cambio de "progreso" para el país).

\section{Legislación sobre los hidrocarburos, antes del porfiriato}

Durante la época virreinal se consideraba que la tierra y las riquezas del subsuelo de la Nueva España le pertenecían al rey de Castilla, por la cesión hecha en la bula papal Inter caetera.

La minería (y entre ellos "los jugos de la tierra" o petróleo) en la época virreinal novohispana se regía, desde el 22 de mayo de 1783, por las Reales Ordenanzas de Minería (expedidas por el rey Carlos III de Borbón) y la Nueva Recopilación (ley IV, título XIII, libro VI). En éstas se sostenía la hipótesis jurídica de que todo lo que se hallase en el subsuelo era propiedad del rey (con el antecedente de que en las Siete Partidas de Alfonso $\mathrm{X}$ El Sabio se establecía que las propiedades de las minas — subsuelo- se hallaban vinculadas al rey).

La primera legislación minera, pensada exclusivamente para la Nueva España, fueron las ordenanzas de Aranjuez de 1793, esta legislación fue importante, porque el rey Carlos IV de España cedió al terrateniente sus derechos reales sobre el carbón, lo hizo por lo que se hallase en el subsuelo de lo que fueran sus dominios. Con el tratado hispano-mexicano de Paz y Amistad de 1836, los derechos del rey de España sobre el subsuelo, y lo que se hallare en él se trasladarían a la nación mexicana. Los empresarios petroleros dirían que la nación mexicana nunca tuvo derechos sobre el petróleo.

Benito Juárez estableció que el carbón y el resto de los minerales, entre ellos el petróleo, estaba sujeto al sistema de denuncios; el particular debía obtener del Estado autorización para explotar dichos recursos.

En el periodo comprendido entre el 14 de noviembre de 1864 y el 6 de noviembre de 1865, dentro de lo que se llama el Segundo Imperio, se otorgaron 38 concesiones petroleras, y en el Decreto de julio 6 de 1865 se ordenó

28 Ibidem, vol. 8, p. 129. 
que nadie podía explotar, entre otros, los lagos de petróleo, sin haber obtenido antes la concesión expresa y formal de las autoridades competentes. ${ }^{29}$

\section{Legislación sobre los hidrocarburos durante el porfiriato}

Las leyes mineras y petroleras fueron simplemente consecuencias de la política económica liberal del gobierno de Porfirio Díaz. Jonathan Brown establece que:

(José Yves) Limantour (secretario de Hacienda) actuaba como nacionalista, pues creía que incluso la riqueza del subsuelo (petróleo y minería) pertenecía a la nación. No obstante, no se podía cargar a esas actividades con impuestos, sin explotarlos antes. Los empresarios nacionales ni podían ni lo harían. Por ello, los políticos tragaron la amarga medicina, y cambiaron leyes para atraer la inversión extranjera. ${ }^{30}$

La legislación en minería, y por ende del petróleo (al ser éste considerado mineral), cambiaría en el porfiriato, y se daría como hipótesis jurídica que el dueño de un terreno donde se hallara el hidrocarburo sería el dueño de éste (según lo establecía la Ley de Minería de 1884 en su artículo 10, fracción IV).

\section{A. Ley de Minería de 1884}

En 1884, durante el gobierno de Manuel González (1880-1884), Pedro Bejarano, Manuel Contreras y Francisco Bulnes presentaron ante el presidente en turno un proyecto de Código de Minería. En este Código de Minería (en el artículo 10, fracción IV), el petróleo, como otros minerales, sería de quien tuviera el "justo título" de propiedad del suelo. Así, en términos de María del Carmen Collado, se privatizó el petróleo.

En comparación con los códigos mineros de los países industrializados, se establecía lo mismo: el petróleo era del dueño de la superficie donde se hallaba. ${ }^{31}$

29 Zenteno, Javier, "La regulación de los hidrocarburos en México", Regulación del sector energético, México, UNAM, Instituto de Investigaciones Jurídicas-Secretaría de Energía, 1997, p. 81.

30 Brown, Jonathan, Petróleo y revolución en México, México, Siglo XXI, 1998, p. 106.

31 Meyer, Lorenzo y Morales, Isidro, Petróleo y nación. La política petrolera en México (1900-1987), México, FCE-Pemex-SEMIP-Colmex, 1990, p. 23. 
En 1887 fue aprobada una Ley que eximía a las minas de carbón, de petróleo y de hierro de todos los impuestos, excepto el del timbre, y por lo tanto nada más pagaban tres centavos por barril (impuesto del timbre).

\section{B. Ley del 6 de julio de 1887}

Esta Ley fiscaliza la explotación del petróleo solamente con el impuesto del timbre; permitiendo una excepción respecto a los demás impuestos.

Según su artículo 4o., el dueño del suelo podría explotar libremente, sin necesidad de concesión especial, los combustibles minerales, los aceites y aguas minerales. La propiedad minera se entendía sólo respecto del subsuelo, y no de la superficie del terreno, la cual continuaría bajo el dominio de su propietario, menos en la parte de ella que necesite ocupar el minero. ${ }^{32}$

\section{Ley de Minería de 1892}

El 4 de junio de 1892 fue promulgada una nueva Ley de Minería. Los minerales tradicionales (oro, plata, platino, mercurio, hierro, cobre, plomo, estaño, sal, piedras preciosas, azufre, etc.) tendrían que ser explotados bajo concesión gubernamental. El artículo 4o. de dicha Ley de Minería decía que el petróleo no necesitaría ser concesionado por Gobierno alguno. Es decir, se confirmaba la ley minera anterior en la cuestión de la explotación del petróleo. En adelante, los petroleros extranjeros sólo necesitaban arreglar los contratos y los arriendos con los propietarios (de las tierras donde hubiera campos petroleros) para perforar sus pozos. Al menos ésta fue la interpretación que muchos extranjeros eligieron dar a las leyes mexicanas. "En el artículo 13 se facultaba a todo habitante de la República mexicana para efectuar libremente en los terrenos de propiedad nacional las exploraciones conducentes al descubrimiento de criaderos minerales". ${ }^{33}$

\section{Ley del Petróleo de 1901}

El 24 de julio de 1901 se promulgaría una Ley exclusivamente petrolera (Ley del Petróleo). Se seguía reconociendo al dueño de determinada superficie como dueño del petróleo que se hallare en el subsuelo de su superficie.

\footnotetext{
32 Zenteno, op. cit., p. 81.

33 Ibidem, p. 82.
} 
También podía el Ejecutivo federal otorgar concesiones en los terrenos fiscales de la Federación.

En la misma Ley del Petróleo de 1901 se establecía, en el artículo 3o., que los que descubrieran petróleo y fueran dueños de la superficie donde hubiera petróleo, podrían exportar libres de todo impuesto los productos naturales (petróleo crudo), refinados, o elaborados que procedan de la explotación (del petróleo) (artículo 3o. de la Ley del Petróleo de 1901); podían (los empresarios petroleros) importar libres de derechos (aduanales), por una sola vez, las máquinas para refinar petróleo o carburos gaseosos de hidrógeno (fracción II, del mismo artículo, de la misma Ley); el capital, invertido en la explotación del petróleo o carburos gaseosos de hidrógeno, era libre por diez años de todo impuesto federal, excepto el del timbre (fracción III, del mismo artículo, de la misma Ley); los empresarios petroleros podían comprar terrenos fiscales federales o terrenos cuya propiedad era del Estado para el establecimiento de sus maquinarias y oficinas al precio de tarifa de los terrenos baldíos; y que los mismos empresarios petroleros podrían expropiar los terrenos si pertenecían a particulares, si indemnizaban al particular.

\section{E. Iniciativa de Ley del Petróleo de 1905}

En 1905, Lorenzo Elízaga, Luis Ibarra y Manuel Fernández Guerra presentaron una iniciativa de ley cuyo objetivo era reintegrar los depósitos petroleros al régimen legal anterior a $1884 .{ }^{34}$ No era un intento de algún socialista o nacionalista para nacionalizar la industria; al contrario, se deseaba alentar la producción petrolera sin obstáculos; por ejemplo, que los propietarios de la tierra y por ende del subsuelo se opusieran a la extracción del crudo.

Porfirio Díaz no mostró entusiasmo alguno por la iniciativa. ${ }^{35}$ Se nombró a un comité para estudiarla, quien a la vez pidió opinión a la Academia Mexicana de Jurisprudencia. Edward Doheny participó como observador de dicho debate; este empresario petrolero estadounidense pensaba que quienes proponían esta ley eran radicales mexicanos deseosos de nacionalizar una industria floreciente. ${ }^{36}$ Estas comisiones prefirieron conservar el estado de las cosas y se desechó la iniciativa.

34 Meyer, op. cit., p. 51.

35 Idem.

36 Meyer y Morales, op. cit., p. 24. 
La importancia de esta iniciativa de ley es que los razonamientos son exactamente los mismos que se esgrimieron en 1938 con el objetivo opuesto: nacionalizar la industria. Se decía que la nación conservaba sus derechos sobre el petróleo, y que el legislador podía retirar la concesión otorgada al dueño de la superficie cuando fuera conveniente a los intereses de la nación. A pesar de que se usaron los mismos argumentos en 1905 y 1938 para defender esta ley y la expropiación petrolera, en 1905 lo que se proponía era facilitar las actividades de las empresas en terrenos particulares, pues al considerar que la exploración petrolera era de utilidad pública, los dueños del predio no podrían oponerse si los petroleros contaban con la anuencia gubernamental para ello.

Sin embargo, según el periódico para los angloparlantes en México, The Mexican Herald, los oficios del Departamento de Estado en Estados Unidos, el embajador de esta nación en nuestro país y el representante británico en México, habría que alarmarse de esta propuesta de ley, porque se pretendía que las empresas con concesiones se registraran como mexicanas según su artículo 144. Con esto no podría haber arbitrio o auxilio de las representaciones extranjeras en México para asistir a sus compatriotas.

\section{F. Ley Minera de 1909}

La Ley Minera, promulgada el 25 de noviembre de 1909, decía (de acuerdo con el artículo 2o.) que eran propiedad exclusiva de los empresarios petroleros, dueños de un terreno en el cual hubiera petróleo, los criaderos o depósitos de combustibles minerales, bajo todas sus formas y variedades y los criaderos o depósitos de materias bituminosas.

Sería interesante que se hiciera un estudio acerca de cuánto en realidad eran las utilidades para cada uno, y en total, de los empresarios petroleros en el porfiriato, porque uno de los reclamos a Francisco I. Madero, según Merril Rippy, era que los petroleros sacrificaban muchas ganancias en impuestos, y se quejaron ante sus gobiernos cuando el gobierno maderista trató de poner nuevos impuestos al petróleo. Cabe mencionar que "el primero de muchos incrementos repentinos de impuestos vino precisamente durante la presidencia de Díaz. En 1910, el Gobierno subió los derechos de fondeo que se cobraban en los puertos, a razón de cincuenta centavos por tonelada de petróleo". Con esto se quiso corregir los excesos del liberalismo económico, junto con otras medidas como la creación de Ferrocarriles Nacionales de México en 1908 y la limitación de privilegios en el terreno petrolero con 
la promulgación de la Ley Minera en 1909, pero el régimen no sospechaba siquiera que estaría cerca de ser derrocado.

\section{G. Contratos-ley}

Las leyes (debiendo ser, por definición, generales y abstractas; es decir, sin "dedicación" alguna o dirigida de manera específica a alguien en particular) beneficiaban a todos los empresarios, sin tomar en cuenta nacionalidad, extranjera o mexicana, que quisieran participar del mercado mexicano petrolero.

Pero los "contratos-ley", como leyes particulares (dirigidas y que dan derechos y obligaciones al Estado mexicano y a un particular), beneficiaron a Edward L. Doheny (propietario de la Huasteca Petroleum Company, estadounidense, y quien le prometió a Porfirio Díaz venderle primero al Gobierno mexicano su compañía si la ponía en venta antes que a la Standard Oil Company o a Henry Clay Pierce) y al inglés Weetman Pearson. ${ }^{37}$

Estos "contratos-ley" debían ser elaborados por la Secretaría de Fomento y aprobados por el poder Legislativo (pero como en el porfiriato no había división de poderes en la práctica, éstos se daban "automáticamente" por aprobados). Los "contratos-ley" tenían como finalidad el hacer posible la exploración y explotación de criaderos de petróleo en el subsuelo mexicano de terrenos fiscales de la Federación y baldíos.

Los primeros "contratos-ley" entre la Federación y Pearson fueron firmados el 18 de enero de 1906, y eran sobre campos petroleros de las entidades federativas de Veracruz, Tabasco, Campeche y Chiapas; le seguirían los de San Luis Potosí y Tamaulipas. ${ }^{38}$ Cabe mencionar que dichos "contratos-ley" fueron signados por Guillermo Puga, subsecretario de Fomento, y Lorenzo Elízaga (pariente político de Porfirio Díaz), representante de Pearson y su compañía S. Pearson \& Son Limited. Estos "contratos-ley" fueron promulgados en el Diario Oficial de los Estados Unidos Mexicanos (lo que ahora es el Diario Oficial de la Federación), el 16 de mayo de 1906, después de la aprobación del Poder Legislativo. El contrato tenía una duración de cincuenta años, contados desde la publicación del mismo (16 de mayo de 1906).

37 Kuntz, Sandra, Las exportaciones mexicanas durante la primera globalización, 1870-1929, México, El Colegio de México, 2010, p. 490.

38 Llanas, Felipe, "México y su petróleo", Boletín del Petróleo, vol. II, núm. 1, julio de 1916, p. 6. 
Los "contratos-ley" entre la Federación y Weetman Pearson eran ventajosos para el empresario inglés respecto a la competencia, en cuanto a que los "contratos-ley" ampliaban las prerrogativas que le daba la Ley de Petróleo de 1901. Por ejemplo, la Ley de Petróleo de 1901 permitía a todo empresario que quisiera incursionar en el mercado mexicano de petróleo la libre exportación de los productos obtenidos en la explotación durante diez años, pero tales "contratos-ley" le permitían a Pearson, y a las empresas que formara para explotar el petróleo mexicano, la libre exportación de los productos obtenidos de la explotación durante tiempo indefinido; la libre importación de maquinaria y equipo por cincuenta años (la Ley de Petróleo de 1901 preveía la misma prerrogativa por una sola vez); la Ley de Petróleo de 1901 establecía que el capital invertido será libre de todo impuesto federal, a excepción del de Timbre por diez años, mientras que en los "contratos-ley" se amplía dicho periodo a cincuenta años; ambos (Ley de Petróleo de 1901 y los "contratos-ley") le permitían a Pearson y a las empresas que formara para explotar el petróleo mexicano, comprar terrenos fiscales de la Federación a precios de terrenos baldíos.

\section{CONCLUSIÓN}

En conclusión, se puede establecer que la legislación petrolera se desarrolló, durante el porfiriato, como parte de un proceso histórico durante el cual se consideraba al petróleo como algo no esencial dada su escasez y que se debía incentivar la inversión extranjera dando facilidades. El interés nacional era que hubiera inversiones dentro del país, aunque fueran extranjeras, y se debían dar ciertas facilidades.

Si se debiera responder si hubo un contraste o no en cuanto a la soberanía o sujeción al capital extranjero en la expedición de leyes petroleras durante el porfiriato respecto al proceso histórico de la Revolución mexicana de 1917 y al cardenismo, se debe contestar que aparentemente no hubo presiones de los empresarios extranjeros, estadounidenses o ingleses, durante el proceso legislativo. La legislación petrolera durante el porfiriato fue escrita por mexicanos y sin intervención extranjera; por lo menos no se sabe de alguna intervención, soborno o presión a través de las representaciones extranjeras en el país para que algún extranjero con interés creado determinara cómo fueran las leyes o no. Sería sorprendente que se hallara alguna fuente histórica legítima y enterada que nos hablara de alguna intervención, soborno o presión a través de las representaciones extranjeras en el país respecto 
al tema. Es más, Doheny decía que el trato con las autoridades mexicanas era cortés y considerado, que no era necesario tener en consideración otras formas (hemos de suponer sobornos y llamados de auxilio a las embajadas); los derechos y privilegios que solicitaba no requerían más que la enunciación de sus buenas razones como empresario. Otra razón para no sospechar de malas actuaciones de empresarios petroleros para cambiar legislaciones mexicanas, era que Enrique Creel como gobernador de Chihuahua subsidiaba las perforaciones que se hicieran, así que los empresarios no sobornaban dando dinero e incluso lo podían recibir.

En el caso del petróleo, en su legislación como en el proceso de su extracción y comercialización, se intentó balancear el interés estadounidense con el británico favoreciendo a este último. Incluso, según el historiador estadounidense Merril Rippy, ${ }^{39}$ el movimiento maderista recibió un cheque de Pierce y/o de Rockefeller de 685000 dólares, aunque en las distintas fuentes que hablan del tema se manejan muchas cifras que van desde los 500000 al millón de pesos o dólares, como expresión de repudio al apoyo de la administración porfirista a los negocios petroleros de Pearson en México. ${ }^{40}$

39 Brown, op. cit., p. 80.

40 García, Jorge, Influencia de los empresarios petroleros norteamericanos en el derrocamiento del régimen porfirista, 1904-1911, México, UNAM, 2011(tesis de licenciatura). 